\title{
[ 48,$]$
}

danit diefiolhen Verfuche, indem jeh es fall des Zinkqueck filhers anwandte. Allein es erfoloto keino Eifenreduction, auch übeshnupt keine Einwirkung, fo dafs im Melfing das Zink durchs Kupfer als chemifch gebunclen betrachtet werden mulis. Mit dur l'rufung anderer Zinklegirungen bin ich jelzt befchufligt und werdo küuftig davon Nachricht beben.

\section{Notis wegen neuer frobachtungen ïber die Intenfität des Erdmagnutismus.}

(Aus einem Scbreiben des Prof. Hansteen au den Herausgeber.)

- Din englifche Admiral tit hat mir in oinem Briefe eine fehr intereffante Reilie von latenfiaisbeobachurngen fuerfandi, die der Capitain des K. Schifts Adventure, P. P. King, mit oinem neiner Intel fitytsapparate, von fireenwich ans bis zur Maldnnadn Ray, am Plata Strom, angeftel!t hat. Die Rzobachtungen in hio Janciro und Maldonado zeigen, dafs die intenfitirsisucen von $0.9 ; 1.0$ und 1,1 ln der Padlichen Halhkugel viel weirer nach $S$ idoftes hinabgehea, als allf der linen neuliel uberfandien Karte (nämlic"l $H_{i e}$ auf Taf. IV dief. Bandes $P$ ), und dits folpytich der yon oer l_inis 0,9 eingefillaftelle Flaclienraum woit arofser if, ale ich noch den damals vo-lia ifenen Benodchtungen febliefsen mirf:e. Selbf am Vorgebirge der guten Hoffnung wird die In:enfilat ksum 0.0 erreichen, fo wie das klounte Minimun iu Afrikp, in ungefifır $15^{\circ}$ fi:dl Breire, kaum 0.8 der ron Hnmbolde aigenomuenen Ein'ipit. Ich erwarte mit Un:geduld eine zweite Sen tung rnn Tiorra rel Fuega oder vou Valdivia. De Lage der Intenfitirslinie 1,? in der Nahe der Hudsolisbay zeigt mir, dals der Winisel der izärkeren Magnetaxe mit der Erdace mehrere Grade grifser if als ich in meiner Theorie angenommen habe, und diefe Berichritullu fr': piat inir die meiften Vifferenzen zwifchen der Tlirorie und Benbachicung z" befeitie gen. Ich habe die englifche Admiraliat dringend erfuciut, langs dem ganzen Aequator Intonfitgtshenbachtungen machen pir la Tivl,

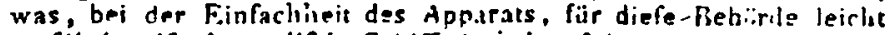
ausfihrbar ift, da englifche Schiffo in jedem Jaure den gallzen Ocean durchkreuzen. - 